\title{
Review
}

\section{Adiponectin resistance and vascular dysfunction in the hyperlipidemic state}

\author{
Rong $\mathrm{LI}^{1}$, Wayne Bond $\mathrm{LAU}^{2}$, Xin Liang $\mathrm{MA}^{1,2, *}$ \\ ${ }^{1}$ Department of Geriatrics, Xijing Hospital, Xi-an 710032, China; ${ }^{2}$ Department of Emergency Medicine, Thomas Jefferson University, \\ Philadelphia, PA 19107, USA
}

\begin{abstract}
Insulin plays an important role in the stimulation of vascular nitric oxide production, with both short term (vasomotility and antithrombotic effects) and long term (smooth muscle cell growth and migration inhibition) benefits. Impaired vasodilatory response to insulin, the hallmark of vascular insulin resistance (IR), has important implications for circulatory pathophysiology. An association between adipokines and IR has been observed in both diabetic and nondiabetic states. Adiponectin (APN) is an insulin-sensitizing adipokine known to stimulate skeletal muscle fatty acid (FA) oxidation and reduce lipid accumulation. Recent demonstrations of potential cross-talk between APN and insulin in vascular function regulation are particularly interesting. The lipid accumulation observed after chronic high-fat (HF) diets and in the obese state may reduce vascular response to APN, a pathologic state termed as APN resistance. This review highlights the importance of insulin sensitivity and APN activity in the maintenance of endothelial function. It explores the relationships between vascular IR and APN resistance in the hyperlipidemic pathological condition, representative of the metabolic syndrome. The investigation of vascular insulin and APN resistance provides not only better understanding of vascular pathophysiology, but also an opportunity for therapeutic targeting in individuals affected by the metabolic syndrome.
\end{abstract}

Keywords: insulin; adiponectin; endothelial dysfunction; nitric oxide; hyperlipidemia

Acta Pharmacologica Sinica (2010) 31: 1258-1266; doi: 10.1038/aps.2010.95; published online 30 Aug 2010

\section{Introduction}

Elevated levels of free fatty acids, insulin resistance (IR), and systemic hypertension all contribute independently to endothelial dysfunction characterized by decreased nitric oxide (NO) bioactivity and vessel wall inflammation, resulting in the initiation and progression of atherosclerosis and coronary heart disease ${ }^{[1-3]}$. Adiponectin $(\mathrm{APN})$, a plasma protein originating from adipose tissue, metabolically mimics insulin, promoting glucose uptake and inhibiting hepatic glucose production $^{[4]}$. Interestingly, APN exerts anti-inflammatory and anti-atherogenic properties via its ability to stimulate vascular endothelial NO production ${ }^{[5]}$. Reduced plasma APN levels or resistance to the metabolic and vascular effects of APN may have a close association with IR and endothelial dysfunction in cardiovascular diseases ${ }^{[6,7]}$. High-fat (HF) diets impair the insulin-signaling cascade by incremental skeletal muscle lipid accumulation ${ }^{[8]}$. Furthermore, evidence of APN resistance in animals subjected to HF diet has been demonstrated by the subsequent blunting of FA oxidation in response to

\footnotetext{
* To whom correspondence should be addressed.

E-mail Xin.Ma@Jefferson.edu

Received 2010-04-06 Accepted 2010-06-22
}

APN stimulation ${ }^{[9]}$. However, the relevancy of defective insulin and APN signaling in the hyperlipidemic vasculature remains elusive. In this review, we discuss the link between the insulin and APN signaling pathway in regulating vascular pathophysiology, especially in hyperlipidemic states, given insights derived from therapeutic dietary, exercise, and pharmaceutical interventions designed to potentiate APN bioactivity/levels, improving insulin sensitivity and endothelial function.

Vascular activity of insulin and vascular insulin resistance (IR)

It has been well-established that insulin stimulates production of endothelial-derived vasodilator nitric oxide (NO). Both insulin and classical vasodilators (including acetylcholine) stimulate NO production by activation of endothelial NO synthase (eNOS) ${ }^{[10]}$. However, insulin activates eNOS without calcium involvement via the insulin receptor tyrosine kinase, setting off a phosphorylation/activation cascade: insulin receptor substrate-1 (IRS-1) is phosphorylated, binding IRS-1, activating phosphoinositide-3 kinase (PI3K), activating 3-phosphoinositide-dependent protein kinase-1 (PDK-1), which phosphorylates protein kinase B (Akt), ultimately phos- 
phorylating and activating eNOS, resulting in increased NO production within minutes ${ }^{[11]}$.

Numerous studies in type 2 diabetic subjects and animal models support a robust association between IR and endothelial dysfunction, measured by impaired endotheliumdependent vasodilation ${ }^{[2]}$. Whether the two states are linked directly or represent manifestations of a common underlying pathology remains uncertain. Of note, some researchers have proposed that endothelial dysfunction may induce $\mathrm{IR}^{[12]}$. Although it has been suggested that endothelial dysfunction may impede glucose uptake by reducing skeletal muscle blood flow $^{[13]}$, this is unlikely to be of major physiological importance.

In the IR state, the vasodilatory and anti-atherogenic functions of insulin (mediated by the PI3K pathway) are impaired. However, its proatherogenic effects (mediated through the MAPK cascade) continue unchecked ${ }^{[14]}$, leading to decreased NO production and increased secretion of ET-1, characteristic of endothelial dysfunction. The blockade of chronic ET-1 receptor (ET-A isoform) has been identified to normalize NOmediated endothelial dysfunction, reducing atheroma formation independent of plasma cholesterol and blood pressure in a mouse model of atherosclerosis ${ }^{[15]}$. The beneficial effects of raloxifene, a selective oestrogen receptor modulator on endothelial function are abolished by wortmannin (PI3K inhibitor ${ }^{[16]}$, which blunts the PI3K-dependent effects of insulin (such as induction of eNOS expression and NO production). In the IR state, there is up-regulation of endothelial cellular adhesion molecules VCAM-1 and E-selectin, and increased interaction between monocytes and endothelial cells ${ }^{[17,18]}$. Morever, proinflammatory signaling stimulated by glucotoxicity and lipotoxicity in dysmetabolic states contributes to shared mechanisms of both IR and endothelial dysfunction. The multiple molecular and cellular mechanisms mediating IR and endothelial dysfunction reflect the complex interactions between inflammatory and metabolic pathways.

\section{APN in vascular physiology and pathophysiology Effects of APN on vascular structure and function}

Studies in animal models and human subjects have demonstrated an association between circulating APN levels and vascular function. Forearm blood flow in human subjects during reactive hyperemia is highly negatively correlated with APN, suggesting that APN contributes to endothelium-dependent vasodilation $^{[19]}$. In human subjects, independent of a correlation with insulin sensitivity, circulating APN levels are positively associated with arterial vasodilation in response to nitroglycerin (thereby endothelium-independent) ${ }^{[20]}$. Furthermore, APN may have direct effects on vascular thrombosis. APN-deficient mice have increased thrombus volume after laser-induced carotid arterial injury; restoration of a normal APN level with an adenovirus expressing APN rescues the thrombotic phenotype ${ }^{[21]}$. APN may suppress atherosclerosis via reduction of collagen-induced platelet aggregation ${ }^{[21]}$, suppression of expression of vascular adhesion molecules scavenger receptors ${ }^{[22]}$, suppression of the proliferation of smooth muscle cells (SMCs) and their directed migration to platelet-derived growth factor-BB, inhibition of growth factorstimulated ERK signaling in human aortic SMC ${ }^{[23]}$, inhibition tumor necrosis factor (TNF) level and resultant inflammatory TNF effects on endothelial function through a cAMP-PKA dependent pathway ${ }^{[24]}$. Recent accumulating evidence has demonstrated $\mathrm{APN}^{\prime}$ s anti-inflammatory actions are related to 5'-AMP-activated protein kinase (AMPK)-induced activation of endothelial nitric oxide (eNOS), with subsequent release of bioavailable NO from endothelium cells ${ }^{[25]}$. Furthermore, APN may also have angiogenic propoerties, as it has been shown to stimulate differentiation of human umbilical vein endothelium cells (HUVECs) into capillary-like structures by promoting cross-talk between AMP-activated protein kinase and Akt signaling within endothelial cells ${ }^{[26]}$ (Figure 1).

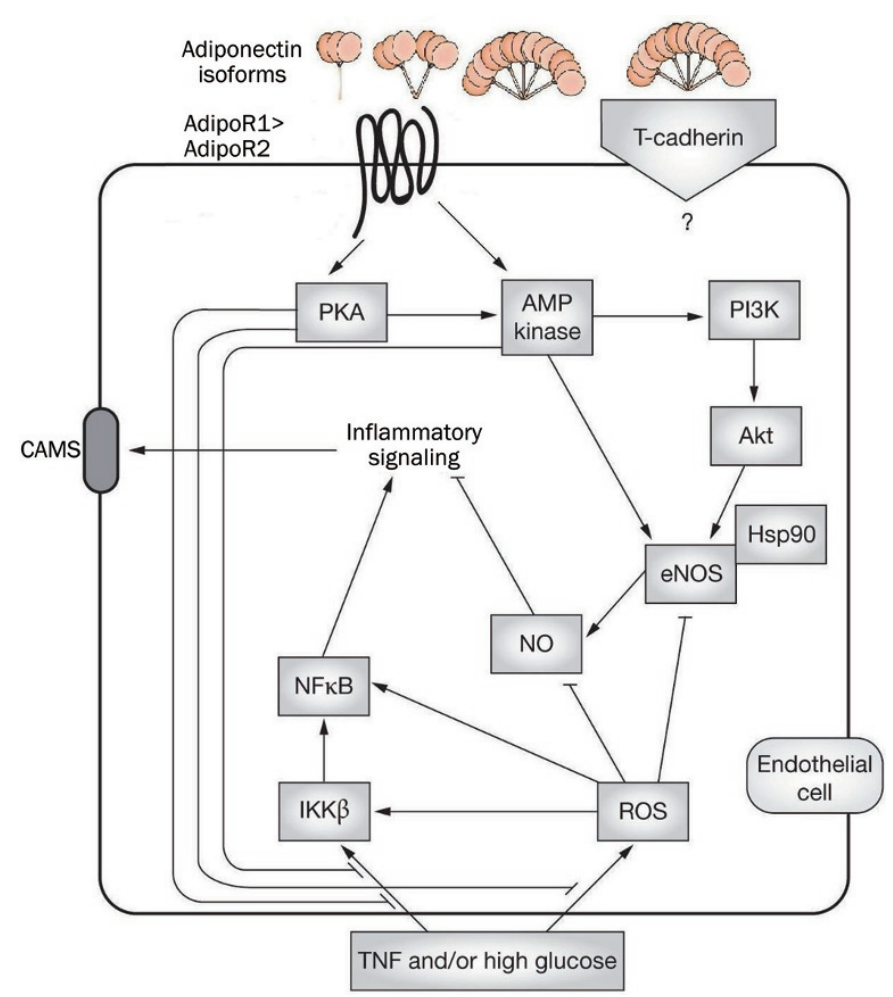

Figure 1. Adiponectin signaling in endothelial cells.

\section{Role of APN in metabolic and vascular diseases}

APN has recently received a great deal of attention due to its beneficial effects on metabolic disorders and ischemia/ reperfusion injury. There is marked down-regulation of APN in obesity-linked diseases such as coronary artery disease and type 2 diabetes ${ }^{[6]}$. A complex polypeptide consisting of four distinct domains, including a globular domain, adiponentin automatically self-associates into larger structures (trimers, hexamers, dodecamers). APN facilitates glucose uptake and increases fatty acid (FA) oxidation in peripheral tissues via stimulation of AMPK activity ${ }^{[27]}$. Interestingly, AMPK stimu- 
lation is induced by both globular and full-length APN in skeletal muscles; only the full-length APN form stimulates AMPK in the liver ${ }^{[27]}$. The activation of AMPK has been shown to phosphorylate and inhibit acetyl-CoA carboxylase (ACC), with a consequent reduction in the malonyl-CoA content, thereby derepressing carnitine palmitoyl-transferase 1 activity and increasing fatty-acid oxidation ${ }^{[28]}$. AMPK also increases glucose uptake via GLUT4 translocation, reducing the rate of glycogen synthesis, and shifting glucose metabolism toward lactate production in skeletal muscle cells ${ }^{[29]}$, decreasing hepatic expression of molecules involved in gluconeogenesis such as phosphoenolpyruvate carboxykinase (PEPCK) and glucose-6-phosphatase (G6Pase) ${ }^{[30]}$.

A recent study has shown the treatment of $\mathrm{C} 2 \mathrm{C} 12$ myocytes with APN for $6 \mathrm{~h}$ significantly increased peroxisome proliferator-activated receptor- $\alpha$ (PPAR- $\alpha$ ) ligand activity and concomitant fatty-acid oxidation in vitro ${ }^{[31]}$. Lipoatrophic or obese diabetic mice supplemented with exogenous APN or subjected to APN overexpression demonstrated increased in vivo insulin sensitivity and decreased liver and skeletal muscle TG content ${ }^{[32]}$. Increased expression of PPAR-a target genes CD36, acyl-coenzyme A oxidase, and uncoupling protein 2 in the mice suggests that APN increased fatty-acid combustion and energy consumption at least partly via PPAR-a activation. Another study attributes the involvement of AMPK and p38 MAPK in the activation of PPAR-a by APN in muscle cells ${ }^{[33]}$. APN increases the transcriptional activity of PPAR-a and the expression of its target genes, including ACO, CPT1, and FABP3 in $\mathrm{C} 2 \mathrm{C} 12$ myotubes. These effects were suppressed by the overexpression of the dominant-negative form of AMPK. Interestingly, AraA, an AMPK inhibitor, prevented the activation of p38 MAPK, whereas SB203580, a p38 MAPK inhibitor, did not affect AMPK activation, suggesting that p38 MAPK is a downstream signaling factor of $\mathrm{AMPK}^{[33]}$. Taken together, these results suggest that APN stimulates FA oxidation in muscle cells by the sequential activation of AMPK, p38MAPK, and PPAR-a.

Recently, APN-deficient mice were successfully established by gene targeting. The APN knockout mouse shows delayed clearance of free FA in plasma, low levels of fatty-acid transport protein 1 messenger RNA in muscle, high levels of TNF- $\alpha$ messenger RNA in adipose tissue, and high plasma TNF-a concentrations $^{[34]}$.

APN knockout mice exhibit profound neointimal hyperplasia despite normal glucose and lipid metabolism while being fed a normal diet ${ }^{[35]}$. These data suggest that neointimal injury does not accelerate as a result of abnormal glucose/lipid metabolism, but is instead directly caused by APN deficiency. APN transgenic/apo-E-knockout mice were protected against atherosclerosis compared with apoE-knockout mice ${ }^{[22]}$, emphasizing the role of APN as an endogenous anti-atherogenic factor, with hypoadiponectinemia playing an important role in the atherosclerotic process. Thus, therapeutic approaches increasing plasma APN concentration may be useful in protecting against atherosclerosis development, as well as preventing restenosis after angioplasty.
A study recently published by our group demonstrated that endothelial dysfunction development in APN knock out mice, evidenced by a markedly reduced response to acetylcholine, was attributed to increased superoxide and peroxynitrite production, increased NO inactivation, and decreased basal NO production. Pretreatment with superoxide scavenger Tiron significantly, but incompletely restored vascular vasodilatory response to ACh. Exogenous administration of the globular domain of APN to APN knock out mice in vivo reduced aortic superoxide production, increased bioactive $\mathrm{NO}$, and normalized vasodilatory response to $\mathrm{ACh}^{[36]}$. In addition, in the face of hyperlipidemic injury, APN protected endothelial function by promoting eNOS activity, inhibiting iNOS activity, preserving bioactive $\mathrm{NO}$, and attenuating reactive oxygen species (ROS) production ${ }^{[37]}$. The mechanisms underlying APN's ability to balance NO availability while simultaneously suppressing endothelial ROS generation reside in the AMPK-eNOS and PKA-ROS-suppression signal transduction pathway ${ }^{[38]}$; documented crosstalk between these two pathways is that upstream AMP kinase kinase LKB1(serine threonine protein kinase II) can be phosphorylated by PKA ${ }^{[39]}$, further contributing to activation of the AMPK-eNOS pathway.

\section{Vascular dysfunction in metabolic syndrome (hyper- lipidemia and diabetes) Hyperlipidemia and vascular dysfunction}

It is well-established that hyperlipidemia impairs endothelial function in experimental animals. Vessels removed from HF diet animals exhibit markedly abnormal endothelium-dependent vascular relaxation to substances such as acetylcholine and thrombin, whereas vasodilation, in response to agents acting directly on the vascular smooth muscle (such as nitroglycerin, sodium nitroprusside or SNAP), remain unchanged ${ }^{[37]}$. When considering where endothelial dysfunction in hyperlipidemia might originate, among the most likely mechanisms is the decreased synthesis of bioactivated NO. Besides its vasodilatory effects, NO has many reported antiatherogenic properties, including reducing platelet aggregability ${ }^{[40]}$, limiting vascular smooth muscle cell proliferation ${ }^{[41]}$, inhibiting adhesion molecule expression in endothelium ${ }^{[42]}$, inhibiting neutrophil and monocyte adhesion to the endothelium ${ }^{[43,44]}$, and preventing monocyte chemotaxis ${ }^{[45]}$. Chronic provision of $L$-arginine to the diets of hypercholesterolemic rabbits has been reported to improve endothelium-dependent vasodilation and reduce the extent of atherosclerotic lesions ${ }^{[46]}$.

Also contributive to hyperlipidemia-mediated endothelial dysfunction is the increased production of reactive oxygen species (ROS, such as superoxide anion) and resultant abundance of reaction product peroxynitrite ${ }^{[37]}$. Membrane-associated $\mathrm{NAD}(\mathrm{P}) \mathrm{H}$-dependent oxidases, which can be activated by PKC in the hyperlipidemic condition, is the primary source of superoxide anion ${ }^{[47]}$. Peroxynitrite, the swift reaction product of $\mathrm{NO}$ and superoxide anion [rate $\left.5 \times 10^{9}(\mathrm{~mol} / \mathrm{L})^{-1} \cdot \mathrm{s}^{-1}\right]^{[48]}$, and resultant protein nitration are considered the respective mediator and marker of various ROS/RNS-induced vascular damage, such as atherosclerotic lesions ${ }^{[49]}$. 


\section{Diabetes and vascular function}

Subjects suffering diabetes and at risk for cardiovascular disease have reduced maximum microvascular vasodilatory capacity ${ }^{[50]}$. Although the determinants of microvascular vasodilatory capacity are incompletely understood, it is not surprising that the endothelium, having such a central role in the regulation of various vascular functions including tone, has been implicated in the observed hemodynamic changes. Reduced maximum microvascular vasodilatory capacity may be a marker of endothelial dysfunction in the microcirculation. Women with a history of gestational diabetes mellitus are prone to developing pre-eclampsia as well as type 2 diabetes later in life ${ }^{[51]}$. Both conditions are associated with vascular endothelial dysfunction ${ }^{[51]}$. Knock and colleagues reported abnormal endothelial function in isolated small arteries taken from normotensive women with gestational diabetes mellitus during caesarean section ${ }^{[52]}$. Atop exhibiting endothelial dysfunction, diabetic patients also demonstrate impaired vascular smooth muscle cell function, evidenced by diminished vasorelaxation response to nitroglycerin/SNP and other endothelium-independent vasodilating agents ${ }^{[53]}$. Fleischhacker and colleagues have demonstrated that diabetic smooth muscle contractility is augmented due to changes in subcellular $\mathrm{Ca}^{2+}$ distribution. Additionally, increased $\mathrm{O}_{2}{ }^{-}$production in diabetes contributes to smooth muscle dysfunction via diminished activity and expression of soluble guanylyl cyclase (sGC) and cGMP-dependent protein kinase type I (cGKI) in VSMC ${ }^{[54,55]}$. VSMCs isolated from diabetic GK rats exhibit marked resistance to insulin-mediated upstream signaling via the IRS-1/ PI3K pathway. This resistance results in marked impairment in downstream myosin-bound phosphatase (MBP) activation, which is accompanied by increased myosin lightchain (MLC)20 phosphorylation and VSMC contraction. In addition, diabetes causes elevations in Rho kinase activity in VSMCs leading to myosin-bound subunit (MBS) phosphorylation, which further inactivates MBP, causing excessive VSMC contractility ${ }^{[56,57]}$. Abnormalities in endothelial and vascular smooth muscle cell function compoundly contribute to subsequent atherosclerosis and vascular complications in DM.

\section{Interrelationship between insulin signaling and APN signaling}

Role of APN in regulation of insulin signaling

The adipocyte-derived protein adiponectin has been proposed to play important roles in the regulation of energy homeostasis and insulin sensitivity. Winzell and colleagues uncovered a potential dual role of APN in relation to insulin secretion. In normal pancreatic islets, APN $(5 \mu \mathrm{g} / \mathrm{mL})$ had no significant effect on insulin secretion. However, in mice islets rendered insulin resistance by $\mathrm{HF}$ feeding, APN inhibited insulin secretion at $2.8 \mathrm{mmol} / \mathrm{L}$ glucose $(P<0.01)$, but augmented insulin secretion at $16.7 \mathrm{mmol} / \mathrm{L}$ glucose $(P<0.05)^{[58]}$. Human mutations of the APN gene result in impaired multimerization of $\mathrm{APN}$, and are consequently linked to increased risk for type 2 diabetes development ${ }^{[59]}$. Animal studies reveal transgenic mice (homozygous null for APN) developed hyperglycemia and hyperinsulinemia under normal conditions or on a high fat diet ${ }^{[60]}$. However, injections of exogenous APN in obese mice decreased plasma glucose and FA levels by suppressing liver glucose production and oxidizing fatty acids in muscle, thereby ameliorating $\operatorname{IR}^{[61,62]}$. Furthermore, treatment of type 2 diabetic patients with rosiglitazone, a PPARY agonist (an insulin sensitizing agent class), can attenuate IR via APN production stimulation ${ }^{[63]}$.

Mullen and colleagues demonstrated both APN and insulin resistance in rats fed a high saturated-fat diet. The animals exhibited a blunted FA oxidation response to globular APN, as well as decreased maximal insulin-stimulated glucose transport ${ }^{[9]}$. Later studies involving HF fed rats revealed the loss of APN's stimulatory effect on FA oxidation preceded the increase in plasmalemmal FA transporters. Through resultant accumulation of intramuscular diacylglycerol (DAG) and ceramide, insulin signaling was consequently blunted, and impaired maximal insulin-stimulated glucose transport in skeletal muscle was observed ${ }^{[64]}$. Bruce and colleagues studied obese subjects with no significant IR, but discovered they had decreased serum APN levels. The observation of blunted activation of AMPK by globular APN in obese muscle furthermore suggested the development of APN resistance in obesity $^{[65]}$. In summation, APN likely is an important mediator in obesity or HF diet-induced IR.

Further studies have been carried out to explore the effects of APN on IR and insulin signaling transduction. DietzSchroeder and colleagues showed that APN inhibited adipocyte secretion of IR-inducing cytokines, including IL-6, IL-8 and monocyte chemotactic protein-1 (MCP-1 $)^{[66]}$. The regulation of these adipocytokines (already established to be related to obesity and diabetes) by APN suggest a molecular link between obesity and skeletal muscle IR. Recently, Fiaschi and colleagues reported the ability of APN in trans-activation of insulin receptor ${ }^{[67]}$. More specifically, APN stimulation produces a transient burst of reactive oxygen species (ROS), and causes the oxidation/inhibition of protein-tyrosine phosphatase (PTP) 1B in hepatic cells. APN then causes increased association of PTP1B with the insulin receptor, ultimately provoking a ligand-independent trans-phosphorylation of insulin receptor. These results demonstrated APN trans-activate the insulin receptor by redox-dependent and ligand-independent fashions.

\section{Role of insulin in regulation of APN signaling}

APN rapidly and potently stimulates AdipoR1 in myotubes derived from lean, healthy individuals ${ }^{[68]}$. In contrast, myotubes isolated from obese patients, obese diabetic patients, and patients who had lost significant weight after bariatric surgery were no longer stimulated by $\mathrm{APN}^{[68]}$. The incapacity of skeletal muscle of obese and diabetic individuals to respond to exogenous APN may be further suppressed as a result of impaired AdipoR1 gene regulation.

MKR mice express dominant-negative mutant insulin-like growth factor (IGF)-I receptors in skeletal muscle. Muscle, liver, and adipose tissue isolated from these mice were found 
to be insulin resistant ${ }^{[69]}$. The mice exhibited elevated APN levels, reduced glucose response to APN acute supplementation; furthermore, chronic APN treatment failed to improve insulin sensitivity and glucose tolerance ${ }^{[69]}$, although investigation into APN receptor mRNA levels and APN stimulated phosphorylation of AMPK in skeletal muscle and liver similar between MKR and wild-type mice ${ }^{[69]}$. Thus APN resistance evident in MKR mice may be the result of IR. Utilizing a mouse model with adipocyte insulin receptor knock out, Lin and colleagues detected hyperadiponectinemia, with normal levels of APN receptor-1 and -2 (AdipoR1/R2) ${ }^{[70]}$. Moreover, exogenous APN administration was unable to decrease glucose levels or induce AMPK activation, consistent with a state of APN resistance ${ }^{[70]}$. These results further support IR may play a crucial role in the impairment of APN's effect.

Tsuchida and colleagues ${ }^{[71]}$ observed that the expression of AdipoR1/R2 appears to be inversely correlated with plasma insulin levels in vivo. Interestingly, the incubation of hepatocytes or myocytes with insulin reduced the expression of AdipoR1/R2 via the phosphoinositide 3-kinase/Foxo1dependent pathway in vitro. Moreover, there is significantly decreased AdipoR1/R2 in skeletal muscle and adipose tissue isolated from the leptin-deficient insulin resistant $o b / o b$ mouse model ${ }^{[71]}$. This was correlated with decreased APN binding to membrane fractions of skeletal muscle, and decreased AMPK activation by APN. Similarly, Inukai and colleagues ${ }^{[72]}$ found that insulin had an inhibitory effect on AdipoR1 expression, in a mechanism mediated by the PI3K-dependent pathway rather than the MAPK pathway. In contrast to Inukai, Staiger and colleagues ${ }^{[73]}$ reported that insulin did not directly modify AdipoR1 mRNA expression in human skeletal muscle cells. These discrepancies may be due to differences in animal model, cell types, or conditions used in these various studies. More studies will be needed to clarify the role of insulin in the regulation of $\mathrm{APN}$ receptor expression.

\section{Pathogenic role of insulin resistance in hyperlipidemia- induced vascular dysfunction}

Increased diacylglycerol and ceramide in hyperlipidemia has been shown to activate PKC, decrease IRS-1-associated PI3K activity, and inhibit phosphorylation/activation of $\mathrm{Akt}^{[74,75]}$. These signal transduction effects may decrease eNOS activity and NO production. In addition, Apolipoprotein (apo) CIII, a small protein that resides in multiple copies on the surface of very-low-density lipoprotein (VLDL) and low-density lipoprotein (LDL) ${ }^{[76]}$, inhibits the IRS-1/PI3K/Akt/eNOS pathway via activation of PKC $\beta$ in human umbilical vein endothelial cells $^{[77]}$. Plasma levels of apoCIII is a crucial link between dyslipidemia and IR in vascular endothelial cells with consequential deleterious effects on their atheroprotective functions.

Plasma free fatty acid (FFA) levels play a crucial role in insulin's vasodilatory and metabolic effects. Infusion of triglycerides in rats raises circulating FFA levels, causing significant impairment in skeletal muscle capillary recruitment. During a glucose clamp procedure, a $40 \%$ decrease in glucose disposal was observed in the rats, with steady state plasma insulin levels of approximately $600 \mathrm{pm}^{[78]}$. In lean women, acute elevation of FFA levels impairs capillary recruitment and acetylcholine-mediated vasodilation before and during hyperinsulinemia ${ }^{[79]}$. Furthermore, the vasodilatory actions of insulin are improved when FFA levels are lowered in obese women $^{[79]}$. The inverse relationship between capillary recruitment and FFA levels, with simultaneous changes in insulinmediated glucose uptake, is at least partly responsible for FFA-induced microvascular dysfunction in the development of obesity-related IR and hypertension.

More importantly, IR induced by hyperlipidemia plays a crucial pathogenic role in endothelial dysfunction. In the setting of systemic IR, insulin has reduced effects only on PI3KAkt pathway, leading to an imbalance between the PI3K- and MAPK-dependent functions of insulin as discussed above ${ }^{[14]}$. The intact MAPK pathway promotes secretion of ET-1, activates cation pumps ${ }^{[80]}$, augments expression of adhesion molecules VCAM-1 and E-selectin, and increases monocyte adhesion to endothelium ${ }^{[81]}$, ultimately increasing inflammation and thrombosis which may contribute to pivotal early events in the pathogenesis of hypertension. Meanwhile, metabolic IR is usually accompanied by decompensatory hyperglycemia. Hyperglycemia contributes greatly to endothelial dysfunction. The glycocalyx, a layer of proteoglycans coating the endothelium, provides vessel wall protection. Hyperglycermia injures the glycocalyx, increasing vascular vulnerability and mediating vascular dysfunction ${ }^{[82]}$. Hyperglycemia also reduces physiologic levels of endothelial NO in the microcirculation via calpain-dependent decreased association of the regulatory protein Hsp90 with eNOS. Inhibition of calpain activity during hyperglycemia attenuates leukocyte-endothelium interactions and preserves endothelial NO release ${ }^{[83]}$. Additionally, hyperglycemia induces a series of cellular events that increase $\mathrm{NO}$ inactivation by interaction with superoxide anion produced by the mitochondria ${ }^{[84]}$. Increased superoxide anion production activates the hexosamine pathway, which further diminishes NOS activation by protein kinase $\mathrm{Akt}^{[85]}$. These processes likely recruit extracellular xanthine oxidase, which exacerbates further the oxidative stress ${ }^{[86]}$. Superoxide anion also increases intracellular production of advanced glycation end products (AGEs) ${ }^{[84]}$, which further increase production of oxygen-derived free radicals. The binding of AGE with its receptor (RAGE) activates consequent intracellular enzymatic superoxide oxide production ${ }^{[87]}$.

Taken together, hyperlipidemia, hyperglycemia and compensatory hyperinsulinemia in the presence of diabetes contribute independently to endothelial dysfunction. In the dysmetabolic state, the underlying mechanisms involved proinflammatory lipotoxicity and glucotoxicity upon the endothelium and pathway-specific impairment of PI3K. The molecular and cellular mechanisms that mediate IR in hyperlipidemia-induced endothelial dysfunction are multiple and reflect complex interactions between inflammatory and metabolic pathways (Figure 2). 


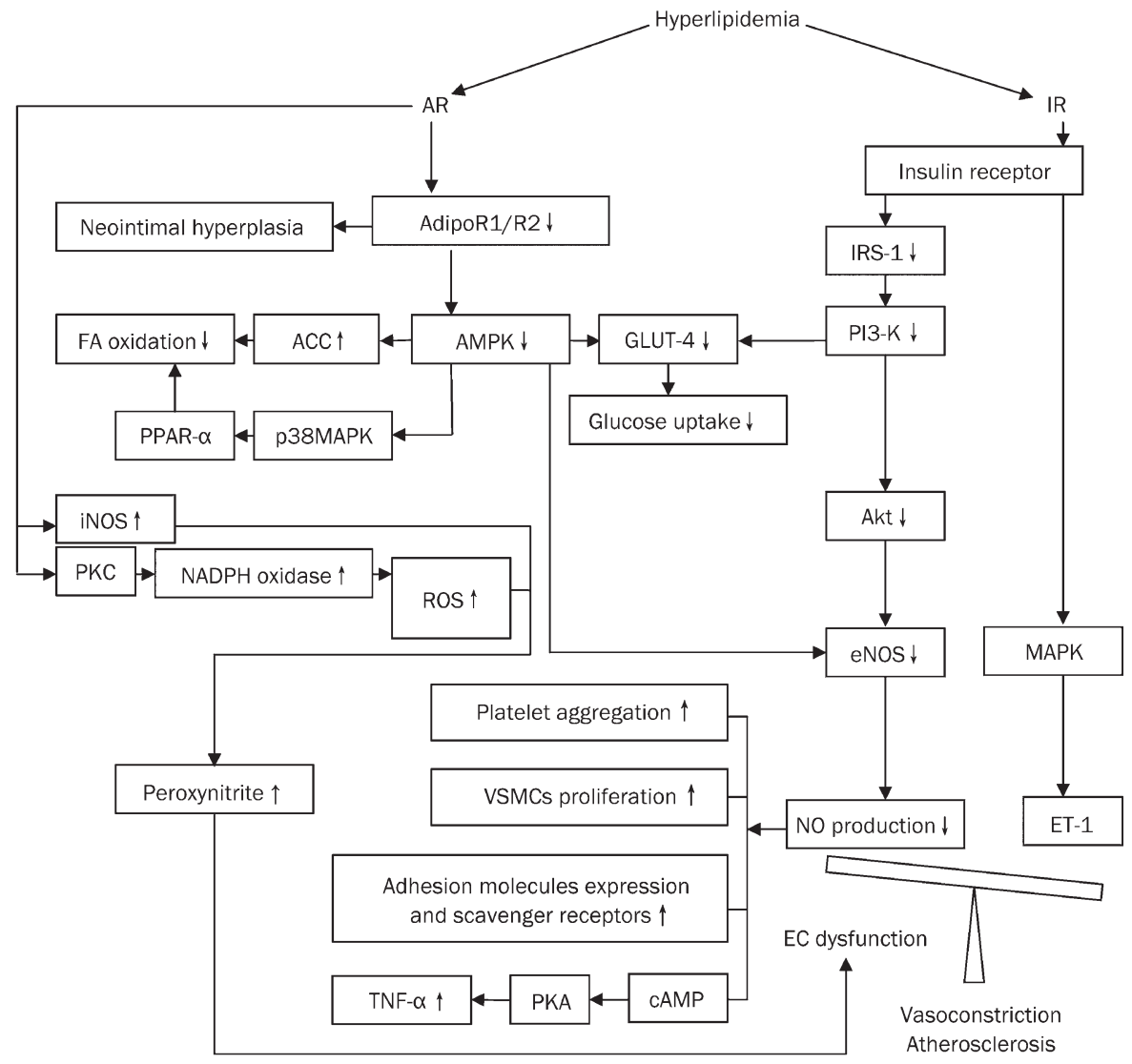

Figure 2. Adiponectin resistance (AR) and hyperlipidemic vascular pathophysiology.

\section{Summary}

The etiology of vascular dysfunction in the hyperlipidemic state is complex. The mechanisms currently identified include the insulin-resistance specific pathway (decreasing NO bioavailability), the APN-resistance specific pathway (decreasing NO bioavailability, oxidative/nitrative stress augmentation), and insulin/APN resistance cross talk (causing intracellular signal transduction disturbance) related phenomena. Although further study is necessary to completely elucidate the mechanisms behind hyperlipidemic endothelial dysfunction, it is likely that a combination of therapeutic approaches targeting multiple mechanisms will yield the most beneficial effect on metabolic and cardiovascular health.

\section{Acknowledgements}

This work was supported by the following grants: $\mathrm{NIH}$ HL-63828, American Diabetes Association Research Award 7-08-RA-98, American Heart Association Grant-in-Aid 0855554D (to XLM), Emergency Medicine Foundation Career Development Grant (to WL) and National Natural Science Foundation of China 30700308 (to RL).

\section{References}

1 Ferri C, Desideri G, Baldoncini R, Bellini C, De Angelis C, Mazzocchi $\mathrm{C}$, et al. Early activation of vascular endothelium in nonobese, nondiabetic essential hypertensive patients with multiple metabolic abnormalities. Diabetes 1998; 47: 660-7.

2 Steinberg HO, Chaker H, Leaming R, Johnson A, Brechtel G, Baron
APN. Obesity/insulin resistance is associated with endothelial dysfunction. Implications for the syndrome of insulin resistance. J Clin Invest 1996; 97: 2601-10.

3 Steinberg HO, Tarshoby M, Monestel R, Hook G, Cronin J, Johnson A, et al. Elevated circulating free fatty acid levels impair endotheliumdependent vasodilation. J Clin Invest 1997; 100: 1230-9.

4 Berg AH, Combs TP, Du X, Brownlee M, Scherer PE. The adipocytesecreted protein Acrp30 enhances hepatic insulin action. Nat Med 2001; 7: 947-53.

5 Chen H, Montagnani M, Funahashi T, Shimomura I, Quon MJ. Adiponectin stimulates production of nitric oxide in vascular endothelial cells. J Biol Chem 2003; 278: 45021-6.

6 Hotta K, Funahashi T, Arita Y, Takahashi M, Matsuda M, Okamoto $Y$, et al. Plasma concentrations of a novel, adipose-specific protein, adiponectin, in type 2 diabetic patients. Arterioscler Thromb Vasc Biol 2000; 20: 1595-9.

7 Ouchi N, Ohishi M, Kihara S, Funahashi T, Nakamura T, Nagaretani $\mathrm{H}$, et al. Association of hypoadiponectinemia with impaired vasoreactivity. Hypertension 2003; 42: 231-4.

8 Lee JS, Pinnamaneni SK, Eo SJ, Cho IH, Pyo JH, Kim CK, et al. Saturated, but not $n-6$ polyunsaturated, fatty acids induce insulin resistance: role of intramuscular accumulation of lipid metabolites. J Appl Physiol 2006; 100: 1467-74.

9 Mullen KL, Smith AC, Junkin KA, Dyck DJ. Globular adiponectin resistance develops independently of impaired insulin-stimulated glucose transport in soleus muscle from high-fat-fed rats. Am J Physiol Endocrinol Metab 2007; 293: E83-90.

10 Montagnani M, Chen H, Barr VA, Quon MJ. Insulin-stimulated activation of eNOS is independent of $\mathrm{Ca}^{2+}$ but requires phosphorylation by Akt at Ser(1179). J Biol Chem 2001; 276: 30392-8. 
11 Hartell NA, Archer HE, Bailey CJ. Insulin-stimulated endothelial nitric oxide release is calcium independent and mediated via protein kinase B. Biochem Pharmacol 2005; 69: 781-90.

12 Pinkney JH, Stehouwer CD, Coppack SW, Yudkin JS. Endothelial dysfunction: cause of the insulin resistance syndrome. Diabetes 1997; 46 Suppl 2: S9-13.

13 Laakso M, Edelman SV, Brechtel G, Baron APN. Decreased effect of insulin to stimulate skeletal muscle blood flow in obese man. A novel mechanism for insulin resistance. J Clin Invest 1990; 85: 1844-52.

14 Jiang ZY, Lin YW, Clemont A, Feener EP, Hein KD, Igarashi M, et al. Characterization of selective resistance to insulin signaling in the vasculature of obese Zucker (fa/fa) rats. J Clin Invest 1999; 104: 447-57.

15 Barton M, Haudenschild CC, d'Uscio LV, Shaw S, Munter K, Luscher TF. Endothelin $\mathrm{ET}_{\mathrm{A}}$ receptor blockade restores NO-mediated endothelial function and inhibits atherosclerosis in apolipoprotein E-deficient mice. Proc Natl Acad Sci USA 1998; 95: 14367-72.

16 Wong CM, Yung LM, Leung FP, Tsang SY, Au CL, Chen ZY, et al. Raloxifene protects endothelial cell function against oxidative stress. Br J Pharmacol 2008; 155: 326-34.

17 Kautzky-Willer A, Fasching P, Jilma B, Waldhausl W, Wagner OF. Persistent elevation and metabolic dependence of circulating E-selectin after delivery in women with gestational diabetes mellitus. J Clin Endocrinol Metab 1997; 82: 4117-21.

18 Knudsen ST, Foss CH, Poulsen PL, Bek T, Ledet T, Mogensen CE, et al. E-selectin-inducing activity in plasma from type 2 diabetic patients with maculopathy. Am J Physiol Endocrinol Metab 2003; 284: E1-6.

19 Tan KC, Xu A, Chow WS, Lam MC, Ai VH, Tam SC, et al. Hypoadiponectinemia is associated with impaired endothelium-dependent vasodilation. J Clin Endocrinol Metab 2004; 89: 765-9.

20 Fernandez-Real JM, Castro A, Vazquez G, Casamitjana R, LopezBermejo A, Penarroja G, et al. Adiponectin is associated with vascular function independent of insulin sensitivity. Diabetes Care 2004; 27 : 739-45.

21 Kato $\mathrm{H}$, Kashiwagi $\mathrm{H}$, Shiraga M, Tadokoro S, Kamae T, Ujiie H, et al. Adiponectin acts as an endogenous antithrombotic factor. Arterioscler Thromb Vasc Biol 2006; 26: 224-30.

22 Okamoto Y, Kihara S, Ouchi N, Nishida M, Arita Y, Kumada M, et al. Adiponectin reduces atherosclerosis in apolipoprotein E-deficient mice. Circulation 2002; 106: 2767-70.

23 Arita Y, Kihara S, Ouchi N, Maeda K, Kuriyama H, Okamoto Y, et al. Adipocyte-derived plasma protein adiponectin acts as a plateletderived growth factor-BB-binding protein and regulates growth factorinduced common postreceptor signal in vascular smooth muscle cell. Circulation 2002; 105: 2893-8.

24 Ouchi N, Kihara S, Arita Y, Okamoto Y, Maeda K, Kuriyama H, et al. Adiponectin, an adipocyte-derived plasma protein, inhibits endothelial NF-kappaB signaling through a cAMP-dependent pathway. Circulation 2000; 102: 1296-301.

25 Motoshima H, Wu X, Mahadev K, Goldstein BJ. Adiponectin suppresses proliferation and superoxide generation and enhances eNOS activity in endothelial cells treated with oxidized LDL. Biochem Biophys Res Commun 2004; 315: 264-71.

26 Ouchi N, Kobayashi H, Kihara S, Kumada M, Sato K, Inoue T, et al. Adiponectin stimulates angiogenesis by promoting cross-talk between AMP-activated protein kinase and Akt signaling in endothelial cells. J Biol Chem 2004; 279: 1304-9.

27 Yamauchi T, Kamon J, Minokoshi Y, Ito Y, Waki H, Uchida S, et al. Adiponectin stimulates glucose utilization and fatty-acid oxidation by activating AMP-activated protein kinase. Nat Med 2002; 8: 1288-95.

28 Dagher Z, Ruderman N, Tornheim K, Ido Y. Acute regulation of fatty acid oxidation and AMP-activated protein kinase in human umbilical vein endothelial cells. Circ Res 2001; 88: 1276-82.

29 Ceddia RB, Somwar R, Maida A, Fang X, Bikopoulos G, Sweeney G. Globular adiponectin increases GLUT4 translocation and glucose uptake but reduces glycogen synthesis in rat skeletal muscle cells. Diabetologia 2005; 48: 132-9.

30 Lochhead PA, Salt IP, Walker KS, Hardie DG, Sutherland C. 5-Aminoimidazole-4-carboxamide riboside mimics the effects of insulin on the expression of the 2 key gluconeogenic genes PEPCK and glucose-6phosphatase. Diabetes 2000; 49: 896-903.

31 Yamauchi T, Kamon J, Waki H, Imai Y, Shimozawa N, Hioki K, et al. Globular adiponectin protected ob/ob mice from diabetes and ApoEdeficient mice from atherosclerosis. J Biol Chem 2003; 278: 2461-8.

32 Yamauchi T, Kamon J, Waki H, Terauchi Y, Kubota N, Hara K, et al. The fat-derived hormone adiponectin reverses insulin resistance associated with both lipoatrophy and obesity. Nat Med 2001; 7: $941-$ 6.

33 Yoon MJ, Lee GY, Chung JJ, Ahn YH, Hong SH, Kim JB. Adiponectin increases fatty acid oxidation in skeletal muscle cells by sequential activation of AMP-activated protein kinase, p38 mitogen-activated protein kinase, and peroxisome proliferator-activated receptor alpha. Diabetes 2006; 55: 2562-70.

34 Maeda N, Shimomura I, Kishida K, Nishizawa H, Matsuda M, Nagaretani $\mathrm{H}$, et al. Diet-induced insulin resistance in mice lacking adiponectin/ACRP30. Nat Med 2002; 8: 731-7.

35 Matsuda M, Shimomura I, Sata M, Arita Y, Nishida M, Maeda N, et al. Role of adiponectin in preventing vascular stenosis. The missing link of adipo-vascular axis. J Biol Chem 2002; 277: 37487-91.

36 Cao Y, Tao L, Yuan Y, Jiao X, Lau WB, Wang Y, et al. Endothelial dysfunction in adiponectin deficiency and its mechanisms involved. J Mol Cell Cardiol 2009; 46: 413-9.

37 Li R, Wang WQ, Zhang H, Yang X, Fan Q, Christopher TA, et al. Adiponectin improves endothelial function in hyperlipidemic rats by reducing oxidative/nitrative stress and differential regulation of eNOS/iNOS activity. Am J Physiol Endocrinol Metab 2007; 293: E1703-8.

38 Ouedraogo R, Wu X, Xu SQ, Fuchsel L, Motoshima H, Mahadev K, et al. Adiponectin suppression of high-glucose-induced reactive oxygen species in vascular endothelial cells: evidence for involvement of a cAMP signaling pathway. Diabetes 2006; 55: 1840-6.

39 Collins SP, Reoma JL, Gamm DM, Uhler MD. LKB1, a novel serine/ threonine protein kinase and potential tumour suppressor, is phosphorylated by cAMP-dependent protein kinase (PKA) and prenylated in vivo. Biochem J 2000; 345: 673-80.

40 Kader KN, Akella R, Ziats NP, Lakey LA, Harasaki H, Ranieri JP, et al. eNOS-overexpressing endothelial cells inhibit platelet aggregation and smooth muscle cell proliferation in vitro. Tissue Eng 2000; 6: 241-51.

41 Garg UC, Hassid A. Nitric oxide-generating vasodilators and 8-bromocyclic guanosine monophosphate inhibit mitogenesis and proliferation of cultured rat vascular smooth muscle cells. J Clin Invest 1989; 83: 1774-7.

42 Tarin C, Gomez M, Calvo E, Lopez JA, Zaragoza C. Endothelial nitric oxide deficiency reduces MMP-13-mediated cleavage of ICAM-1 in vascular endothelium: a role in atherosclerosis. Arterioscler Thromb Vasc Biol 2009; 29: 27-32.

43 Ma XL, Weyrich AS, Lefer DJ, Lefer AM. Diminished basal nitric oxide release after myocardial ischemia and reperfusion promotes neutrophil adherence to coronary endothelium. Circ Res 1993; 72 : 403-12.

44 Ewart MA, Kohlhaas CF, Salt IP. Inhibition of tumor necrosis factor 
alpha-stimulated monocyte adhesion to human aortic endothelial cells by AMP-activated protein kinase. Arterioscler Thromb Vasc Biol 2008; 28: 2255-7.

45 Magazine HI, Chang J, Goumon Y, Stefano GB. Rebound from nitric oxide inhibition triggers enhanced monocyte activation and chemotaxis. J Immunol 2000; 165: 102-7.

46 Boger RH, Bode-Boger SM, Brandes RP, Phivthong-ngam L, Bohme $M$, Nafe $R$, et al. Dietary $L$-arginine reduces the progression of atherosclerosis in cholesterol-fed rabbits: comparison with lovastatin. Circulation 1997; 96: 1282-90.

47 Mohazzab KM, Kaminski PM, Wolin MS. NADH oxidoreductase is a major source of superoxide anion in bovine coronary artery endothelium. Am J Physiol 1994; 266: H2568-72.

48 Koppenol WH. The basic chemistry of nitrogen monoxide and peroxynitrite. Free Radic Biol Med 1998; 25: 385-91.

49 Beckmann JS, Ye YZ, Anderson PG, Chen J, Accavitti MA, Tarpey MM, et al. Extensive nitration of protein tyrosines in human atherosclerosis detected by immunohistochemistry. Biol Chem Hoppe Seyler 1994; 375: 81-8.

50 Jaap AJ, Hammersley MS, Shore AC, Tooke JE. Reduced microvascular hyperaemia in subjects at risk of developing type 2 (non-insulindependent) diabetes mellitus. Diabetologia 1994; 37: 214-6.

51 Garner PR, D'Alton ME, Dudley DK, Huard P, Hardie M. Preeclampsia in diabetic pregnancies. Am J Obstet Gynecol 1990; 163: 505-8.

52 Knock GA, McCarthy AL, Lowy C, Poston L. Association of gestational diabetes with abnormal maternal vascular endothelial function. $\mathrm{Br} J$ Obstet Gynaecol 1997; 104: 229-34.

53 Tan KC, O K, Chow WS, Ai VH, Siow YL, Lam KS. Hyperhomocysteinemia and impaired vasomotor function in type 2 diabetes mellitus. Eur J Clin Invest 2002; 32: 328-34.

54 Pfeifer A, Klatt P, Massberg S, Ny L, Sausbier M, Hirneiss C, et al. Defective smooth muscle regulation in cGMP kinase I-deficient mice. EMBO J 1998; 17: 3045-51.

55 Fleischhacker E, Esenabhalu VE, Spitaler M, Holzmann S, Skrabal F, Koidl B, et al. Human diabetes is associated with hyperreactivity of vascular smooth muscle cells due to altered subcellular $\mathrm{Ca}^{2+}$ distribution. Diabetes 1999; 48: 1323-30.

56 Sandu OA, Ragolia L, Begum N. Diabetes in the Goto-Kakizaki rat is accompanied by impaired insulin-mediated myosin-bound phosphatase activation and vascular smooth muscle cell relaxation. Diabetes 2000; 49: 2178-89.

57 Begum N, Sandu OA, Ito M, Lohmann SM, Smolenski A. Active Rho kinase (ROK-alpha) associates with insulin receptor substrate-1 and inhibits insulin signaling in vascular smooth muscle cells. J Biol Chem 2002; 277: 6214-22.

58 Winzell MS, Nogueiras R, Dieguez C, Ahren B. Dual action of adiponectin on insulin secretion in insulin-resistant mice. Biochem Biophys Res Commun 2004; 321: 154-60.

59 Waki H, Yamauchi T, Kamon J, Ito Y, Uchida S, Kita S, et al. Impaired multimerization of human adiponectin mutants associated with diabetes. Molecular structure and multimer formation of adiponectin. J Biol Chem 2003; 278: 40352-63.

60 Yang B, Brown KK, Chen L, Carrick KM, Clifton LG, McNulty JA, et al. Serum adiponectin as a biomarker for in vivo PPARgamma activation and PPARgamma agonist-induced efficacy on insulin sensitization/ lipid lowering in rats. BMC Pharmacol 2004; 4: 23.

61 Combs TP, Berg AH, Obici S, Scherer PE, Rossetti L. Endogenous glucose production is inhibited by the adipose-derived protein Acrp30. J Clin Invest 2001; 108: 1875-81.

62 Purushotham A, Wendel AA, Liu LF, Belury MA. Maintenance of adiponectin attenuates insulin resistance induced by dietary conjugated linoleic acid in mice. J Lipid Res 2007; 48: 444-52.

63 Combs TP, Wagner JA, Berger J, Doebber T, Wang WJ, Zhang BB, et al. Induction of adipocyte complement-related protein of 30 kilodaltons by PPARgamma agonists: a potential mechanism of insulin sensitization. Endocrinology 2002; 143: 998-1007.

64 Mullen KL, Pritchard J, Ritchie I, Snook LA, Chabowski A, Bonen A, et al. Adiponectin resistance precedes the accumulation of skeletal muscle lipids and insulin resistance in high-fat-fed rats. Am J Physiol Regul Integr Comp Physiol 2009; 296: R243-51.

65 Bruce CR, Mertz VA, Heigenhauser GJ, Dyck DJ. The stimulatory effect of globular adiponectin on insulin-stimulated glucose uptake and fatty acid oxidation is impaired in skeletal muscle from obese subjects. Diabetes 2005; 54: 3154-60.

66 Dietze-Schroeder D, Sell H, Uhlig M, Koenen M, Eckel J. Autocrine action of adiponectin on human fat cells prevents the release of insulin resistance-inducing factors. Diabetes 2005; 54: 2003-11.

67 Fiaschi T, Buricchi F, Cozzi G, Matthias S, Parri M, Raugei G, et al. Redox-dependent and ligand-independent trans-activation of insulin receptor by globular adiponectin. Hepatology 2007; 46: 130-9.

68 McAinch AJ, Steinberg GR, Mollica J, O'Brien PE, Dixon JB, Macaulay $\mathrm{SL}$, et al. Differential regulation of adiponectin receptor gene expression by adiponectin and leptin in myotubes derived from obese and diabetic individuals. Obesity (Silver Spring) 2006; 14: 1898-904.

69 Kim CH, Pennisi P, Zhao H, Yakar S, Kaufman JB, Iganaki K, et al. MKR mice are resistant to the metabolic actions of both insulin and adiponectin: discordance between insulin resistance and adiponectin responsiveness. Am J Physiol Endocrinol Metab 2006; 291: E298305.

70 Lin HV, Kim JY, Pocai A, Rossetti L, Shapiro L, Scherer PE, et al. Adiponectin resistance exacerbates insulin resistance in insulin receptor transgenic/knockout mice. Diabetes 2007; 56: 1969-76.

71 Tsuchida A, Yamauchi T, Ito Y, Hada Y, Maki T, Takekawa S, et al. Insulin/Foxo1 pathway regulates expression levels of adiponectin receptors and adiponectin sensitivity. J Biol Chem 2004; 279 : 30817-22.

72 Inukai K, Nakashima Y, Watanabe M, Takata N, Sawa T, Kurihara S, et al. Regulation of adiponectin receptor gene expression in diabetic mice. Am J Physiol Endocrinol Metab 2005; 288: E876-82.

73 Staiger H, Kaltenbach S, Staiger K, Stefan N, Fritsche A, Guirguis A, et al. Expression of adiponectin receptor mRNA in human skeletal muscle cells is related to in vivo parameters of glucose and lipid metabolism. Diabetes 2004; 53: 2195-201.

74 Bourbon NA, Sandirasegarane L, Kester M. Ceramide-induced inhibition of Akt is mediated through protein kinase Czeta: implications for growth arrest. J Biol Chem 2002; 277: 3286-92.

75 Montell E, Turini M, Marotta M, Roberts M, Noe V, Ciudad CJ, et al. DAG accumulation from saturated fatty acids desensitizes insulin stimulation of glucose uptake in muscle cells. Am J Physiol Endocrinol Metab 2001; 280: E229-37.

76 Aalto-Setala K, Weinstock PH, Bisgaier CL, Wu L, Smith JD, Breslow JL. Further characterization of the metabolic properties of triglyceride-rich lipoproteins from human and mouse apoC-III transgenic mice. J Lipid Res 1996; 37: 1802-11.

77 Kawakami A, Osaka M, Tani M, Azuma H, Sacks FM, Shimokado K, et al. Apolipoprotein CIII links hyperlipidemia with vascular endothelial cell dysfunction. Circulation 2008; 118: 731-42.

78 Clerk LH, Rattigan S, Clark MG. Lipid infusion impairs physiologic insulin-mediated capillary recruitment and muscle glucose uptake in vivo. Diabetes 2002; 51: 1138-45.

79 de Jongh RT, Serne EH, Ijzerman RG, de Vries G, Stehouwer CD. Free fatty acid levels modulate microvascular function: relevance for 
obesity-associated insulin resistance, hypertension, and microangiopathy. Diabetes 2004; 53: 2873-82.

80 Al-Khalili L, Kotova O, Tsuchida H, Ehren I, Feraille E, Krook A, et al. ERK1/2 mediates insulin stimulation of $\mathrm{Na}^{+}, \mathrm{K}^{+}$-ATPase by phosphorylation of the alpha-subunit in human skeletal muscle cells. J Biol Chem 2004; 279: 25211-8.

81 Montagnani M, Golovchenko I, Kim I, Koh GY, Goalstone ML, Mundhekar AN, et al. Inhibition of phosphatidylinositol 3-kinase enhances mitogenic actions of insulin in endothelial cells. J Biol Chem 2002; 277: 1794-9.

82 Nieuwdorp M, van Haeften TW, Gouverneur MC, Mooij HL, van Lieshout MH, Levi M, et al. Loss of endothelial glycocalyx during acute hyperglycemia coincides with endothelial dysfunction and coagulation activation in vivo. Diabetes 2006; 55: 480-6.

83 Stalker TJ, Skvarka CB, Scalia R. A novel role for calpains in the endothelial dysfunction of hyperglycemia. FASEB J 2003; 17: 1511-3. 84 Nishikawa T, Edelstein D, Du XL, Yamagishi S, Matsumura T, Kaneda Y, et al. Normalizing mitochondrial superoxide production blocks three pathways of hyperglycaemic damage. Nature 2000; 404: 787-90.

85 Du XL, Edelstein D, Dimmeler S, Ju Q, Sui C, Brownlee M. Hyperglycemia inhibits endothelial nitric oxide synthase activity by posttranslational modification at the Akt site. J Clin Invest 2001; 108: 1341-8.

86 Desco MC, Asensi M, Marquez R, Martinez-Valls J, Vento M, Pallardo $\mathrm{FV}$, et al. Xanthine oxidase is involved in free radical production in type 1 diabetes: protection by allopurinol. Diabetes 2002; 51: 111824.

87 Tan KC, Chow WS, Ai VH, Metz C, Bucala R, Lam KS. Advanced glycation end products and endothelial dysfunction in type 2 diabetes. Diabetes Care 2002; 25: 1055-9. 